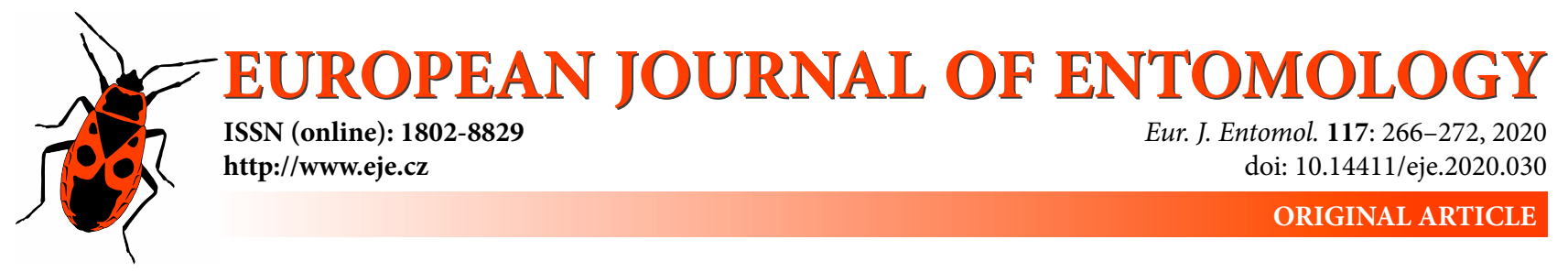

\title{
The effects of mating on the reproductive fitness of Microplitis rufiventris (Hymenoptera: Braconidae)
}

\author{
Esmat M. HEGAZI ${ }^{1}$, Christophe BRESSAC ${ }^{2}$ and Wedad KHAFAGI ${ }^{3}$ \\ ${ }^{1}$ Department of Entomology, Biological Control Lab, Faculty of Agriculture, Alexandria University, Alexandria 22542, Egypt; \\ e-mail: eshegazi@hotmail.com \\ ${ }^{2}$ Department of Entomology, Université de Tours - CNRS, F-37200 Tours, France; e-mail: bressac@univ-tours.fr \\ ${ }^{3}$ Plant Protection Research Institute - Biological Control, Alexandria, Egypt; e-mail: wedadkhafagi20002000@yahoo.com
}

\begin{abstract}
Key words. Hymenoptera, Braconidae, Microplitis rufiventris, parasitoid, Spodoptera littoralis, mating regime, polyandry, progeny production, sex ratio
\end{abstract}

\begin{abstract}
The synovigenic braconid parasitoid, Microplitis rufiventris Kokujev is a promising wasp for use in augmentative releases against young larvae of some noctuid pests, including Spodoptera littoralis (Boisduval), in Egypt. It also has the potential to control the invasive noctuid Spodoptera frugiperda (J.E. Smith) in Africa. M. rufiventris is monandrous in the wild but is polyandrous under some laboratory rearing conditions. S. littoralis larvae were used as hosts to gain an understanding of the influence of mating on wasp-fitness. Newly emerged females ( $0-3 \mathrm{~h}$ old) of $M$. rufiventris were assigned to one of six mating schedules: Virgin females mated once (on day 1, 3 or 5) or 3 times during their life or provided daily with fresh virgin males. These mating schedules affected fecundity, reproductive longevity and sex ratio of the progeny. The life time fecundity of wasps mated on day 5 or mated three times was higher than that of other females, but their reproductive longevity was significantly shorter. In most cases, offspring production per female per day decreased with age. Mated M. rufiventris females produced significantly more progeny than virgin females. The progeny of virgin females consisted only of males, females that mated once had strongly male-biased sex ratios, whereas multi-mated females had a more female-biased sex ratio. More sperm was stored in the spermatheca than the number of daughters produced in any of the mating schedules. Age at first mating affected the lifetime fecundity. At death, the ovaries of mated wasps contained significantly more mature eggs than those of virgin wasps, indicating that mating increased egg production. This information can help enhance the efficiency of parasitoid mass-rearing and their use as biocontrol agents of noctuid pests.
\end{abstract}

\section{INTRODUCTION}

The braconid parasitoid, Microplitis rufiventris Kokujev, 1914 (Hymenoptera: Braconidae) is one of the most important natural enemies of the cotton leaf worm, Spodoptera littoralis (Boisduval, 1933) and several other noctuid insects in Egypt (Hammad et al., 1965). M. rufiventris attacks and can develop in the earlier instars of $S$. littoralis when these larvae still live in clusters near where the eggs were laid. However, the third instar larva is preferred (Hegazi et al., 1977). It is a synovigenic species (i.e. females emerge with a few mature eggs with further egg maturation during the course of their lifetime) (Khafagi et al., 2011). This parasitoid lays a single egg per host and the first three instars feed on the host's haemolymph. The time of parasitoid development from egg to emergence in S. littoralis larvae is ca. $7-8$ days when kept at $27 \pm 1^{\circ} \mathrm{C}$ and $60 \pm 5 \% \mathrm{RH}$. After reaching the late third instar, the wasp larva emerges from its host and spins a cocoon (Hegazi \& Führer, 1985).

Mating in M. rufiventris wasps occurs as soon as both sexes are present. The wasp is monandrous in the wild but is polyandrous under some laboratory rearing conditions, e.g. excess of fresh virgin males and small rearing cages (Hegazi, 1977). In hymenopteran parasitoids mating affects the outcome of various parameters, such as, longevity, lifetime fecundity, progeny production and sex ratio, and some parasitoids must mate to achieve their full reproductive potential (Ridley, 1988; Sagarra et al., 2002). Longevity of insect parasitoids is shortened by energy- and time-consuming activities such as individual interactions, courtship and mating frequency (Domenichini, 1967; Li et al., 1993).

The main parameter affected by mating is the sex ratio. M. rufiventris wasps are arrhenotokous, i.e. fertilized eggs lead to female progeny and unfertilized eggs give rise to males (Godfray, 1994). Sperm stored by females after copulation is a key factor in the control of the sex ratio, because the number of daughters produced are limited by the number of spermatozoa in the spermathecae (Bressac \& Chevrier, 1998; Chirault et al., 2019). Several authors report a gradual shift in the offspring sex ratio from female to 
male biased with the aging of female wasps (Houseweart et al., 1983; Bai \& Smith, 1993; Honda \& Trjapitzin, 1995; Chevrier \& Bressac, 2002). Failures of numerous biological projects involving parasitoid wasps are tentatively attributed to male-biased sex ratios (Wajnberg, 1994). Therefore, successful mass-production of parasitoid must rely on optimally managing the sex ratio (Waage, 1986). Information on fecundity and regulation of sex ratios in parasitoids are important factors for their successful use in the biological control of lepidopteran pests. We chose the koinobiont endoparasitoid $M$. rufiventris as a model for this study of the effect of mating schedule on parasitoid fitness. The results of this study may be useful for the implementation of mass rearing of $M$. rufiventris for use in inundated biological control programs against some noctuid pests. We conducted a laboratory study to compare both fecundity and sex ratio of females that were subjected to different mating schedules.

\section{MATERIALS AND METHODS}

\section{Origin and rearing of insects}

M. rufiventris wasps and the cotton leaf worm, S. littoralis were obtained from a laboratory colony established at Alexandria University. These colonies originated from field crops, including cotton growing in Alexandria, Egypt. S. littoralis larvae were reared on a semi-synthetic diet based on kidney beans (Hegazi \& Schopf, 1984) and were used as hosts for rearing M. rufiventris using methods described by Hegazi \& El-Minshawy (1979). Infusions of field-collected insects were regularly made to eliminate the negative effects of inbreeding in both cultures. Mating in $M$. rufiventris wasps occurs as soon as both sexes emerge from their cocoons. The wasps were provided daily with small droplets of honey to ensure maximum reproductive success.

\section{Test females}

Standardized parasitoid females were obtained as follows: newly moulted third instar larvae of $S$. littoralis were selected for exposure to parasitoids. Oviposition by a mated parasitoid female (1-d old) was followed in $15 \times 60 \mathrm{~mm}$ Petri dishes (3-4 females/ dish) and only one oviposition allowed per host larva. Parasitized larvae were then placed individually in Petri dishes $(1.5 \times 3.5$ $\mathrm{cm})$ and provided daily with fresh diet ad libitum until the adult stage. Experimental females weighed from 1.5 to $1.7 \mathrm{mg}$, with an accuracy of $0.01 \mathrm{mg}$.

\section{Effects of mating schedules on $M$. rufiventris}

The lifetime fecundity, reproductive longevity (i.e. oviposition period) and production of female progeny by M. rufiventris reared on early $3 \mathrm{rd}$ instar larvae of $S$. littoralis were recorded. Freshly emerged females ( $0-3 \mathrm{~h}$ old $)$ were randomly assigned to one of six treatments. The following mating and parasitization schedules were used:

(1) Unmated females, never exposed to males (virgin),

(2) Female mated once on day 1,

(3) Female mated once on day 3,

(4) Females mated once on day 5 ,

(5) Female mated three times, on day 1, 3 and 5 (multi-mating confirmed by observation),

(6) Females each kept throughout their lifespan together with freshly emerged 2-3 virgin males, which were changed daily. For schedules $3 \& 4$, we chose a 3 or 5 day delay before mating because ovipositing $M$. rufiventris have a short lifespan.
For treatments 2-5, the $M$. rufiventris females were individually placed in a small Petri dish $(5 \mathrm{~cm}$ diameter) containing droplets of honey and newly emerged virgin males. Males immediately started chasing the females and a successful mating was when females remained motionless and males stayed attached for about 10-20 s. After mating, each female was then immediately removed. For treatment 5 , mating was observed on day 1 , on day 3 and day 5 , then all wasps were stored separately. For treatment 6 , 2-3 newly emerged virgin males ( $0-1$ day old) were placed daily with a female for $24 \mathrm{~h}$, then removed and new virgin males were introduced the following day. This mating regime was repeated throughout the life of the females.

Nine to twelve females were used in each the mating treatments. All the females were individually allowed to parasitize newly moulted 3rd instar host larvae till death. Each female was provided with $50 \pm 2$ healthy hosts for $3 \mathrm{~h}$ daily. After parasitism, the $S$. littoralis larvae were transferred to the artificial diet. Parasitized larvae were checked every $24 \mathrm{~h}$ until an adult wasp emerged. If a host died (Jones et al., 1986) or did not produce a parasitoid, they were dissected to determine the status of the parasitoid development and the total number of eggs deposited per female. Dissections were made in Pringle's saline solution $(0.75$ $\mathrm{g} \mathrm{NaCl}, 0.035 \mathrm{~g} \mathrm{KCl}$, and $0.021 \mathrm{~g} \mathrm{CaCl}_{2}$ in $100 \mathrm{ml}$ distilled water) using a stereo dissecting microscope (Pringle, 1938). Thus, actual presence or absence of a parasitoid was determined for each of the 50 hosts provided daily to an adult female. This was continued until the female parasitoid died. Females that died before mating or produced no progeny after day 6 of mating were excluded from the analysis, as ovipositing M. rufiventris normally live for 7-10 days (Hegazi, 1977). Parasitization or realized fecundity in each female/mating treatment was calculated by adding the number of hosts that were parasitized or died. There were 9-12 replicates of each treatment (one female per replicate), in a completely randomized design. The recorded data were longevity and fecundity of parasitoid females, and production of female progeny.

Means and standard deviations of parasitization and number of females per parent female per day were calculated. All experiments were done at $25 \pm 1{ }^{\circ} \mathrm{C}, 60 \pm 5 \% \mathrm{RH}$, and 3200 lux provided for $12 \mathrm{~h}$ per day by fluorescent lights.

\section{Egg load at death}

M. rufiventris females each have two ovaries, each with two ovarioles. The egg load of females was recorded by dissecting them after they died, which allowed us to count the mature eggs (323-390 $\mu \mathrm{m}$ long) remaining in the ovarioles. Mature eggs are found in the calyx (eggs to be laid first) and reservoir regions (ready for transfer to the calyx region for oviposition). Dissection was done in Ringer's Solution under a stereo-zoom microscope at a magnification of $60-90 \times$, using two \# 0 insect micro-pins, the abdomen of each female was teased apart and the ovaries removed. Subsequently, the number of eggs present in the calyx region and lateral oviduct egg reservoir were counted by further teasing the tissues apart so that the individual eggs were released.

\section{Sperm in spermathecae}

As the number of spermatozoa transferred to a female wasp decreases with the number of females a male has inseminated (Ruther et al., 2009; Chirault et al., 2016), females in another treatment $(n=15)$ were each mated once by virgin males $(0-3 \mathrm{~h}$ old) when they were one day old and then kept for 2 days without hosts after which they were killed and their spermathecae dissected and transferred to a drop of saline, stained with DAPI and the number of sperm counted using a fluorescence microscope (method in Uzbekov et al., 2017). 

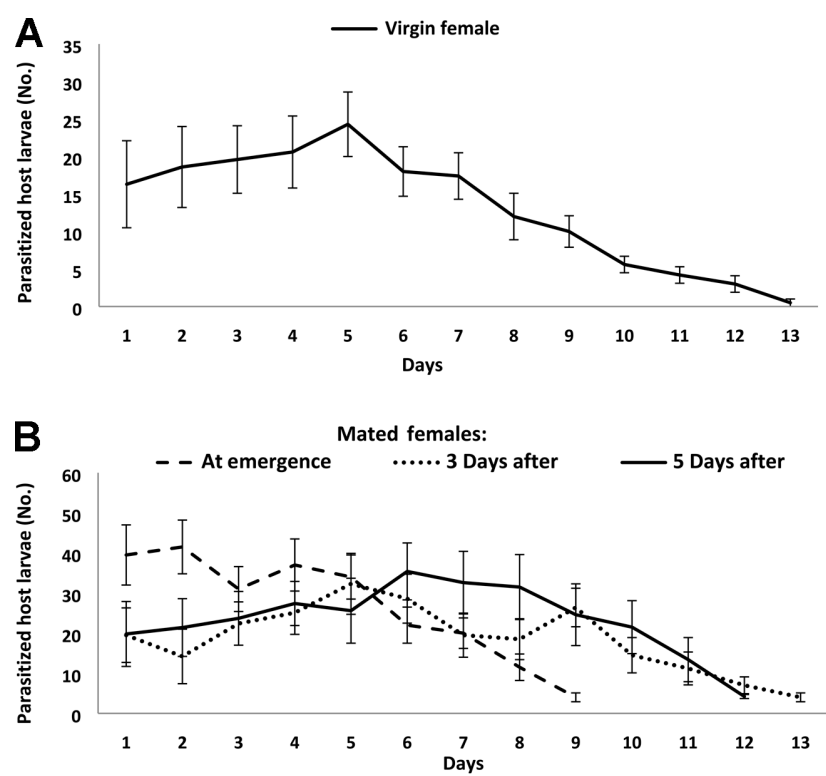

C

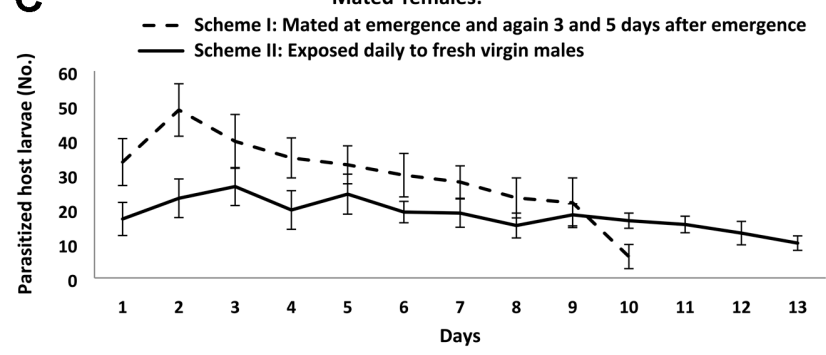

Fig. 1. Mean number of hosts parasitized $( \pm S D)$ by females each day in the different mating treatments $(A, B$ and $C)$.

\section{Statistical analysis}

The experimental design was completely randomized and balanced (equal numbers of wasps were assigned randomly to each treatment). The data presented as percentages were normalized using a logarithmic transformation. Data were subjected to analysis of variance (one-way ANOVA) to determine the differences between means. When there was a significant difference, a least significant differences test was used. The $\alpha$ level for significance testing was set at 0.05 (Winer et al., 1991). Duncan's multiple range test or Student's t-test were used for separating means. Correlation between fecundity and length of the oviposition period was carried out for each mating schedule. Estimates are means \pm SEM, unless otherwise stated.

\section{RESULTS}

\section{Fecundity and reproductive longevity}

Mating schedule significantly affected the average reproductive longevity of female $M$. rufiventris (i.e. oviposition period) $(\mathrm{F}=23.9$; d.f. $=5,58 ; P<0.05)$. Virgin females lived longest $(12.8 \pm 0.3$ days $)$. Females mated once on day 1 had the shortest longevity $(8.4 \pm 0.2$ days $)$, followed by those mated on day $3(11.2 \pm 0.3$ days $)$ or day $5(10.1 \pm$ 0.6 days). Interestingly, the longevity of females mated on days 1,3 and 5 after emergence $(10.3 \pm 0.3$ days) and those provided with freshly emerged virgin males daily $(12.9 \pm$ 0.2 days) was longer than those mated once on day 1 (Table 1). Mated females parasitized significantly $(\mathrm{F}=190.9$; d.f. $=5,58 ; P<0.05)$ more $S$. littoralis larvae than virgin females (Fig. 1).

The mean daily parasitization by $M$. rufiventris females subjected to different mating schedules are shown in Figs 1 and 2. Generally, the number of larvae parasitized daily by $M$. rufiventris changed with age. Parasitization was highest on the $1^{\text {st }}$ to $5^{\text {th }}$ day of a female's adult life and then declined (age dependent parasitization). Percentage parasitism of the wasps that were mated on day 1, 3 and 5 (copulation confirmed by observation) and those provided daily with freshly emerged virgin males differed significantly (Fig. 2), indicating that some of the latter females were mated only once. Although the longevity of females that were mated on day 1, 3 and 5 was significantly shorter than those provided with fresh virgin males daily (Table 1), the former parasitized significantly more larvae than the latter. Mating schedule of female parasitoids significantly affected their life time fecundity $(\mathrm{F}=190.9$; d.f. $=$ 5, 58; $P<0.05$ ) and consequently daily parasitism (Fig. $1 \mathrm{~A}-\mathrm{C})$. The life time fecundity of virgin wasps was 169 \pm 2.0 eggs and $240 \pm 4.7,243 \pm 1.2,281 \pm 1.8$ eggs for females mated once on either day 1,3 or 5 , respectively. The life time fecundity of females mated three times was significantly greater $(298 \pm 4.9$ eggs $)$ than those provided with fresh virgin males daily $(237 \pm 1.9$ eggs) (Table 1$)$. These results indicate that mating stimulates $M$. rufiven-

Table 1. Effect of different mating schedules on the mean ( $\pm \mathrm{SE})$ longevity, life time fecundity, percentage of females in total progeny and mature eggs remaining in the oviducts.

\begin{tabular}{|c|c|c|c|c|c|c|}
\hline & \multirow[b]{2}{*}{$\begin{array}{c}\text { Virgin } \\
(n=12)\end{array}$} & \multicolumn{3}{|c|}{ Mated once on (day, d) } & \multicolumn{2}{|c|}{ Multi-mated } \\
\hline & & $\begin{array}{c}d 1 \\
(n=12)\end{array}$ & $\begin{array}{c}d 3 \\
(n=10)\end{array}$ & $\begin{array}{c}d 5 \\
(n=9)\end{array}$ & $\begin{array}{c}\text { Schedule I } \\
(\mathrm{n}=9)\end{array}$ & $\begin{array}{c}\text { Schedule II } \\
(\mathrm{n}=12)\end{array}$ \\
\hline Rep longevity (days) & $12.8 \pm 0.3 \mathrm{~A}$ & $8.4 \pm 0.2 \mathrm{C}$ & $11.2 \pm 0.3 \mathrm{~B}$ & $10.1 \pm 0.5 \mathrm{~B}$ & $10.3 \pm 0.3 \mathrm{~B}$ & $12.9 \pm 0.2 \mathrm{~A}$ \\
\hline Life time fecundity (eggs) & $169.0 \pm 2.0 \mathrm{D}$ & $240 \pm 4.7 \mathrm{C}$ & $243 \pm 2.2 C$ & $281.0 \pm 1.8 \mathrm{~B}$ & $298.0 \pm 4.9 \mathrm{~A}$ & $237 \pm 1.9 \mathrm{C}$ \\
\hline Female $\%$ of total progeny & $00.0 \pm 0.0 \mathrm{D}$ & $27.2 \pm 0.7 \mathrm{C}$ & $26.2 \pm 1.0 \mathrm{C}$ & $25.1 \pm 0.7 \mathrm{C}$ & $46.4 \pm 1.7 \mathrm{~A}$ & $35.8 \pm 0.9 \mathrm{~B}$ \\
\hline Sperm used for fertilization (\%) & $0.0 \pm 0.0 \mathrm{E}$ & $16.9 \pm 0.8 \mathrm{D}$ & $17.2 \pm 0.6 \mathrm{D}$ & $19.1 \pm 0.7 C$ & $37.4 \pm 0.8 \mathrm{~A}$ & $22.9 \pm 1.7 \mathrm{~B}$ \\
\hline \multicolumn{7}{|l|}{ Remaining eggs in the oviducts: } \\
\hline Reservoir & $24.3 \pm 0.7 \mathrm{C}$ & $27.2 \pm 0.8 \mathrm{~B}$ & $31.7 \pm 1.8 \mathrm{~A}$ & $26.7 \pm 0.9 B C$ & $19 \pm 1.3 \mathrm{D}$ & $29.3 \pm 0.3 A B$ \\
\hline Calyx & $2.9 \pm 0.3 \mathrm{D}$ & $7.5 \pm 0.5 \mathrm{C}$ & $7.9 \pm 0.5 \mathrm{C}$ & $15.0 \pm 0.6 \mathrm{~A}$ & $12.0 \pm 0.6 \mathrm{~B}$ & $11.1 \pm 0.9 \mathrm{~B}$ \\
\hline Total & $27.2 \pm 0.9 \mathrm{D}$ & $34.7 \pm 1.0 \mathrm{~B}$ & $39.6 \pm 1.6 \mathrm{~A}$ & $41.7 \pm 1.4 \mathrm{~A}$ & $31.0 \pm 1.4 \mathrm{C}$ & $39.4 \pm 1.5 \mathrm{~A}$ \\
\hline
\end{tabular}

Note: Within rows, means followed by the same letters are not significantly different $(P<0.05)$. Number between brackets refers to number of available replicates (i.e., 9-12 females) found and used, but data were modified to be from 10 females by testing another females later or exclude data of some excess females. So we had in each case data of 10 females (i.e, replicates) and 6 treatments for statistical analyses. 
A
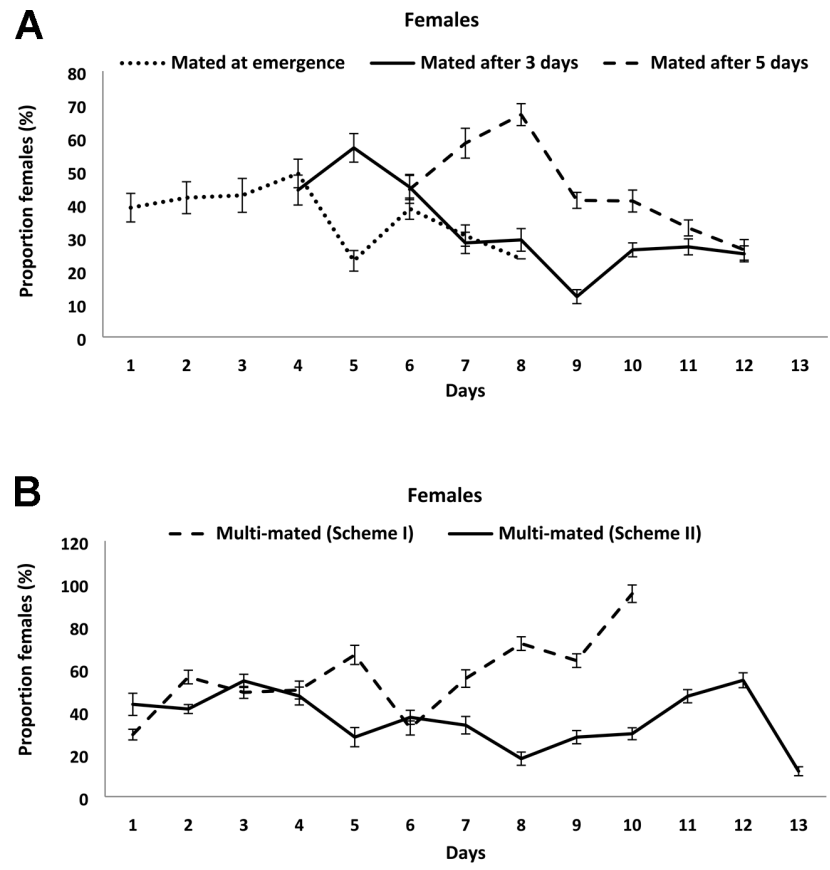

Fig. 2. Mean daily $( \pm S D)$ percentage of female progeny produced by females that: $(A)$ mated only once, either at emergence, 3 days after emergence or 5 days after emergence and (B) mated at emergence and again 3 and 5 days later and those provided daily with fresh males.

tris females to lay more eggs. For example, females mated three times laid 28.9 eggs per day, whereas virgin females laid 13.2 eggs per day. Age at first mating also affected lifetime fecundity. Wasps mated on day 5 , produced more eggs (281 \pm 1.8 eggs) than those mated at emergence $(240 \pm 4.7$ eggs). Also the lifetime fecundity of multi-mated females was significantly higher than that of wasps that mated only once (Table 1), which indicates that mating affects fecundity. For example, the life time fecundity of wasps mated once ranged from 240 to 281 eggs whereas that of multimated wasps was 298 eggs.

Correlations between fecundity and length of the oviposition period were determined for each mating schedule. The correlation ranged from weak for multi-mated females ( 0.6126 mated three times and -0.5291 for those provided with fresh virgin males each day) to very weak for virgin wasps and those mated once.

\section{Progeny sex ratio}

All virgin females produced only males. The progeny sex ratio of single mated females was male-biased and significantly affected by maternal age and when mated $(\mathrm{F}=$ 264.2; d.f. $=5,58 ; P<0.05$ ) (Fig. 2). For single mated females, the number of daughters produced decreased with age (Fig. 2). Single mated females produced significantly lower percentages of female offspring on the first day of oviposition than on subsequent days. Females that mated with males on day 1 , produced $27.2 \% \pm 0.7$ female offspring, those that mated on day $326.1 \% \pm 1.0$ and on day $525.1 \% \pm 0.7$ (Fig. 2A). For multi-mated females, those that were provided with freshly emerged virgin males daily produced a significantly lower percentage of females

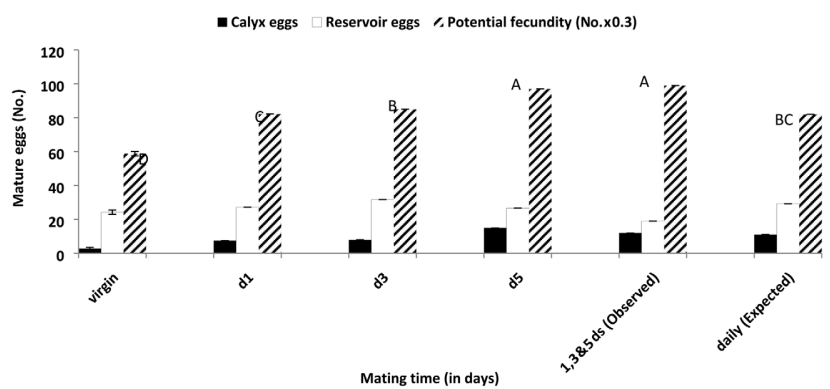

Fig. 3. Unrealized potential fecundity of $M$. rufiventris based on the distribution of mature eggs in the calyx and oviducts of the ovaries of females at death, which were mated in different ways. Bars with the same letter are not significantly different at $P<0.05$.

(35.8\% \pm 0.9 females) than those mated on days 1,3 and 5 $(46.4 \% \pm 1.7$ females) (Table 1$)$.

\section{Sperm in spermathecae}

The number of sperm stored in spermathecae was 370.3 $\pm 8.5, \mathrm{n}=10$, with the minimum 318 and maximum 426 . This is higher than the total number of daughters produced by any of the female wasps. Based on the average number of stored sperm in the spermathecae, the percentage of females in total progeny and total number of eggs laid, it was possible to deduce the percentage of sperm used to fertilize eggs (Table 1). A significantly lower $(\mathrm{F}=1042.5$; d.f. $=5$, $58 ; P<0.05)$ percentage of the sperm was used to fertilize eggs by the wasps that mated only once than those that mated several times.

\section{Realized fecundity and egg load at death}

Two variables were calculated for wasp fecundity: (a) realized fecundity (RF) (i.e. the number of eggs laid during the lifetime of a female) and (b) potential fecundity (PF) (i.e. $\mathrm{RF}+$ the number of eggs remaining in the oviducts of the female wasp at death). Monitoring hosts parasitized by virgin females and the dissection of parasitized hosts revealed that on average of $169 \pm 2$ eggs were laid (RF) and $27 \pm 0.9$ eggs remained in the ovarioles (respectively, 24.3 and 2.9 eggs in the reservoir and calyx), giving a PF of $196 \pm 2.5$ eggs (Fig. 3). Compared to virgin females, wasps mated once on day 1,3 or 5 had higher PFs of 274.7, 282.6 and 322.7 eggs, respectively and their gonads contained significantly more eggs in both the reservoir $(\mathrm{F}=15.1$, d.f. $=5,58 ; P<0.05)$ and calyx $(\mathrm{F}=46.9$, d.f. $=5,58 ; P<$ $0.05)$. Females that were mated on day 1,3 and 5 had the highest PF (329.1 \pm 1.8$)$ (Fig. 3) $(\mathrm{F}=378.8$, d.f. $=5,58 ; P$ $<0.05$ ). At death, the ovarioles of single and multi-mated wasps contained significantly more mature eggs than those of virgin wasps ( $\mathrm{F}=18.2$, d.f. $=5,58 ; P<0.05)$.

\section{DISCUSSION}

Females of parasitoid wasps are considered to be predominantly monandrous (Ridley, 1993). M. rufiventris is also monandrous but can be polyandrous under some laboratory rearing conditions. To determine how this affects the wasp's reproductive output we used 6 mating treatments, including 2 that involved multiple mating. 
M. rufiventris is a haplodiploid wasp, which means that inseminated females can produce both haploid sons (from unfertilized eggs) and diploid daughters (from fertilized eggs). The results indicate that mating provides females with a direct fecundity benefit and that re-mating results in a more female-biased sex ratio. Hence, repeated inseminations did not limit the sperm used in sex allocation as is the case for instance in Nasonia vitripennis (Boulton \& Shuker, 2015).

Mating schedule of female parasitoids significantly affected their daily fecundity and reproductive longevity. Virgin females lived longer than females that were mated once. Mated females had a shorter oviposition period, but parasitized more host larvae than virgin females. This is in accordance with the review by Partridge (1986), who concludes that mating reduces female lifespan in many insects. Our results also indicate that mating stimulates female $M$. rufiventris to lay eggs more quickly. For example, although virgin females lived significantly longer than multi- mated females, the life time fecundity of the later was significantly higher than that of virgin females. Also, the reproductive longevity of multi-mated females was longer than that of those mated once on day 1 . So, multi-mating increased the reproductive longevity compared to that of wasps that mated only once. Different contrasting results are reported by Sagarra et al. (2002): the life time fecundity and the reproductive longevity of virgin and mated females of Anagyrus kamali Moursi (Hymenoptera: Encyrtidae), were not significantly different. In $M$. rufiventris, the fecundity of multi-mated females was significantly greater than that of wasps that mated only once, which indicates that re-mating increases fecundity. Also, at death, a greater number of mature eggs were recorded in the calyx and reservoir regions of ovaries of mated than virgin wasps, which indicates that mating increases egg production.

The present study reveals that the production of progeny by $M$. rufiventris is significantly dependent on the age of the females. Reduced fecundity with age is documented for various species of insects. However, the study of Navasero $\&$ Elzen (1992) found that the clutch size of mated $\mathrm{Mi}$ croplitis croceipes (Cresson) varied cyclically over their life span with egg production peaking in intermediate-aged parasitoids.

The progeny of virgin $M$. rufiventris consisted of only males, whereas mated females produced both females and males and had a strongly male-biased sex ratio. Mated $M$. rufiventris females produced a significantly lower percentage of female offspring in the first few days of oviposition than latter on and in old age it shifted again to producing a greater percentage of males. Because the sex ratio of the offspring of single mated females at emergence changed significantly with age, intermediate-aged females produced a greater percentage of daughters than newly emerged or old parasitoids. The sex ratio the progeny of females mated once at emergence was male biased, whereas that of multi-mated females was female biased. The results indicate that $M$. rufiventris females can control the sex ratio of their progeny by manipulating the percentage of inseminated eggs they lay, and that the sex ratio of the progeny is a function of the time the female is unmated. Similar results are reported by Fauvergue et al. (1998) for the wasp Aphelinus asychis (Hymenoptera: Aphelinidae). They report that females mated late in life produce a more female biased sex ratio of around $60 \%$ females after mating than females mated at emergence $(40-50 \%)$. They also indicate that the sex ratio depends on the time the females remain unmated.

The change in the sex ratio in favour of males might be due to a variety of factors, including sperm depletion, or because most of the sperm load is used earlier due to physiological factors. Previous studies have shown that sex ratio in Trichogramma is affected by maternal age. In studies on T. minutum, Houseweart et al. (1983) and Smith \& Hubbes (1986) both report that young females produce a higher proportion of female offspring than older females. In $M$. rufiventris, as in all arrhenotokous Hymenoptera, males develop from unfertilized eggs and females from fertilized eggs. An increase in the percentage of males with maternal age may therefore just be due to depletion of sperm (Chevrier \& Bressac, 1998, 2002). Sperm is stored in spermathecae in females and the amount present after one mating exceeds the production of female offspring (370 spermatozoa versus $26.1 \%$ of 254 (mean eggs/female), i.e. 66.2 daughters). The potential of the stored sperm is never achieved, with only $26 \%$ of the sperm used to fertilise eggs, which is high compared to most animals (Snook, 2005). Females that were mated several times produced the highest percentage of daughters (46.4\% of 298). Further studies are needed to follow the course of sperm depletion in females with aging, but the minuteness of the spermatheca (a spherical melanised capsule less than $20 \mu \mathrm{m}$ in diameter, unpublished) makes it difficult to obtain such data.

Ridley's (1993) study of the mating behaviour of 99 species of parasitoids revealed that approximately $80 \%$ of the species have to mate only once to attain their optimal sex ratio. However, some parasitoids are polyandrous under laboratory conditions, e.g. Anagyrus kamali Moursi (Sagarra et al., 2001), Campoletis chlorideae Uchida (Dhillon \& Sharma, 2011), N. vitripennis (Boulton \& Shuker, 2015) and, as is shown here, also M. rufiventris. Mating frequency evidently affected the sex ratio of $M$. rufiventris. Based on the average number of sperm stored in spermathecae of females after one mating (370.3 \pm 8.5 sperm/female $)$ and the percentage of female progeny produced by wasps that mated once (26.2\%, sperm-limited females) and several times $(46.4 \%$ ), we deduce that the sperm for about $20.2 \%$ of the fertilized eggs came from sperm stored after a subsequent mating. This may explain why the number of daughters significantly increased when the female mated several times. It also implies that wasp needs new sperm from another mating to produce more daughters. For the mass rearing female parasitoids the cultures should be provided with an abundance of males in order to ensure multiple mating and thus preclude sperm depletion.

Our observations indicate that, both males and females of $M$. rufiventris can mate several times. Chevrier \& Bres- 
sac (2002), Henter (2004) and Boivin (2013) report that, one important factor constraining the offspring production and sex ratio of female wasp is the quality and quantity of sperm they receive from males; multiple mating could help in both respects. Van den Assem (1986) also concludes that mating frequency is likely to increase reproductive success.

The present results revealed differences in wasp sex ratio in the different mating schedules. Singly mated females, do not appear to receive enough sperm for producing the optimum sex ratio. This has also been shown for other parasitoids, such as Dinarmus basalis (Chevrier \& Bressac, 2002) and Spalangia endius (King \& Bressac, 2010). In both these species, multiple mating increases sperm numbers in the spermathecae, but only resulted in an increase in the production of daughters in Dinarmus basalis. The results of the present study indicate that multiple mating is likely to replenish sperm in the spermatheca and increase reproductive success. It is therefore recommended that, in order to ensure a high reproductive success of the $\mathrm{Mi}$ croplitis used for mass rearing, males should regularly be added to the rearing cages.

Understanding the reproductive behaviour of M. rufiventris can help in improving mating success and maximizing fecundity in the laboratory. More work needs to be done to understand the role of multiple mating in determining Microplitis' reproductive strategy, e.g. sperm load/single mating, maximum capacity for storing sperm, when the sperm is used by a female and the dynamics of sperm storage. There may also be an effect of temperature as under laboratory conditions in winter mated wasps appear to produce more daughters than in summer (Hegazi, 1977). Also, although females readily mate several times in the laboratory, there is no information on how often wasps mate in the wild. This could be studied by measuring sperm storage in wild females. Overall our study reveals that a single mating may be insufficient to ensure maximum fecundity. Females provided regularly with males over the course of their lifetime are more likely to parasitize more hosts and produce more daughters than females mated only once. These findings can be used to enhance the efficiency of mass-rearing of parasitoids for use in the biocontrol of noctuid pests, including the invasive noctuid Spodoptera frugiperda (J.E. Smith) in Africa.

CONFLICT OF INTEREST. The authors declare no conflict of interest.

DATA AVAILABILITY STATEMENT. The data that support the findings of this study are available from the corresponding author, upon request.

ACKNOWLEDGEMENTS. This work was conducted with financial support from Campus France, PHC IMHOTEP 2014 PROJET N³1634QH. E.M. Hegazi wishes to thank the Alexander-Von-Humboldt-Foundation for the research scientific donation used in this work. Thanks to F. Yehia for improving the English and typing the article. The authors warmly thank the anonymous reviewers for their suggestions for improving the article.

\section{REFERENCES}

BAI B. \& SмIтH S.M. 1993: Effect of host availability on reproduction and survival of the parasitoid wasp Trichogramma minutum. - Ecol. Entomol. 18: 279-286.

BoIvin G. 2013: Sperm as a limiting factor in mating success in Hymenoptera parasitoids. - Entomol. Exp. Appl. 146: 149155.

Boulton R.A. \& Shuker D.M. 2015: A sex allocation cost to polyandry in a parasitoid wasp. - Biol. Lett. 11: 20150205, 4 pp.

Chevrier C. \& Bressac C. 1998: Offspring and sex ratio are independent of sperm management in Eupelmus orientalis females. -J. Insect Physiol. 44: 351-359.

Chevrier C. \& Bressac C. 2002: Sperm storage and use after multiple mating in Dinarmus basalis (Hymenoptera: Pteromalidae). - J. Insect Behav. 15: 385-398.

Chirault M., Van de Zande L., Hidalgo K., Chevrier C., BresSAC C. \& LÉCUREUIL C. 2016: The spatio-temporal partitioning of sperm by males of the prospermatogenic parasitoid Nasonia vitripennis is in line with its gregarious lifestyle. - J. Insect Physiol. 91-92: 10-17.

Chirault M., Bressac C., Goubault M. \& Lécureuil C. 2019: Sperm limitation affects sex allocation in a parasitoid wasp $\mathrm{Na}$ sonia vitripennis. - Insect Sci. 26: 853-862.

Dhillon M.K. \& Sharma H.C. 2011: Effect of mating and parasitism regimes on progeny production and sex ratio of Campoletis chlorideae Uchida. - Indian J. Exp. Biol. 49: 786-790.

Domenichini G. 1967: Contributo alla conoscenza biologica e tassinomica dei Tetrastichinae paleartici (Hym.; Eulophidae) con particolare riguardo ai materiali dell'Istituto di Entomologia dell'Universita di Torino. - Boll. Zool. Agrar. Bachicolt. 2: $75-110$.

Fauvergue X., Hopper K.R., Antolin M.F. \& Kazmer D.J. 1998: Does time until mating affect progeny sex ratio? A manipulative experiment with the parasitoid wasp Aphelinus asychis. J. Evol. Biol. 11: 611-622.

Godfray H.C.J. 1994: Parasitoids, Behavioral and Evolutionary Ecology. Princeton University Press. Princeton, NJ, 473 pp.

Hammad S.M., El-Minshawy A.M. \& Salama A. 1965: Studies on Microplitis rufiventris Kok. (Hym.; Braconidae). - Bull. Entomol. Soc. Egypt 49: 215-219.

Hegazi E.M. 1977: Further Studies on Certain Natural Enemies Attacking the Cotton Leafworm in Alexandria Region. Ph.D. Thesis, Faculty of Agriculture, Alexandria University, 183 pp.

Hegazi E.M. \& El-Minshawy A.M. 1979: Laboratory technique for mass rearing of Microplitis rufiventris Kok. (Braconidae; Hymenoptera) and internal parasite of the cotton leafworm, Spodoptera littoralis (Boisd.) (Noctuidae; Lepidoptera). Boll. Lab. Entomol. Agr. F. Silvestri 36: 205-210.

HEGAZI E.M. \& FÜHRER E. 1985: Instars of Microplitis rufiventris (Hym.; Braconidae) and their relative developmental speed under different photoperiods. - Entomophaga 30: 231-243.

Hegazi E.M. \& Schopf R. 1984: The influence of temperature on consumption and utilization of artificial diet by Spodoptera littoralis (Boisd.) (Lepidoptera: Noctuidae). - Z. Angew. Entomol.97: 321-326.

Hegazi E.M., El-Minshawy A.M. \& Hammad S.M. 1977: Mass rearing of the Egyptian cotton leafworm, Spodoptera littoralis (Boisd.) on semi-artificial diet. In: Proceedings of Second Arab Pesticide Conference. Tanta University Press, Tanta, pp. 61-70.

Henter H. 2004: Constrained sex allocation in a parasitoid due to variation in male quality. - J. Evol. Biol. 17: 886-896.

Honda J.Y. \& TRJAPITZIN S.V. 1995: A species description and biological comparison between a new species of Telenomus 
Haliday (Hymenoptera: Scelionidae) and Trichogramma platneri Nagarkatti (Hymenoptera: Trichogrammatidae): Two egg parasitoids of Sabulodes aegrotata (Guenée) (Lepidoptera: Geometridae). - Pan-Pacif. Entomol. 71: 227-236.

Houseweart M.W., Jennings D.T. \& Southard S.G. 1983: Progeny production by Trichogramma minutum Riley (Hymenoptera: Trichograrnmatidae) utilizing eggs of Choristoneura fumiferana (Lepidoptera: Tortricidae) and Sitotroga cerealella (Lepidoptera: Gelechiidae). — Can. Entomol. 115: 1245-1252.

Jones D., Hones G., Rudnicka M., Click A., Reck-Malleczewen V. \& Iwaya M. 1986: Pesudoparasitism of host Trichoplusia ni by Chelonus spp. as a new model system for parasite regulation of host physiology. - J. Insect Physiol. 32: 315-328.

Khafagi W.E., Hegazi E.M., Andersson P. \& Schlyter F. 2011: Does host size and feeding status influence the egg load of $\mathrm{Mi}$ croplitis rufiventris (Hymenoptera: Braconidae)? - Ann. Entomol. Soc. Am. 104: 221-228.

King B.H. \& BRESSAC C. 2010: No fitness consequence of experimentally induced polyandry in a monandrous wasp. - Behaviour 147: 85-102.

Li S.Y., Sirois G., Lee D.L., Maurice C. \& Henderson D.E. 1993 Effects of female mating status and age on fecundity, longevity and sex ratio in Trichogramma minutum (Hymenoptera: Trichogrammatidae). - J. Entomol. Soc. Brit. Colum. 90: 61-66.

NAVASERo R. \& Elzen G. 1992: Influence of maternal age and host deprivation on egg production and parasitization by Microplitis croceipes (Hym.: Braconidae). - Entomophaga 37: 37-44.

PARTRIDGe L. 1986: Sexual activity and life span. In Collatzs K.G. \& Sohal R.S. (eds): Insect Aging Strategies and Mechanisms. Springer, Berlin, pp. 45-54.

Pringle J.H.W. 1938: Proprioception in insects. - J. Exp. Biol. 15: 101-103.

RIDLEY M. 1993: Clutch size and mating frequency in parasitic Hymenoptera. - Am. Nat. 142: 893-910.

RIDLEY M. 1988: Mating frequency and fecundity in insects. Biol. Rev. 63: 509-549.
Ruther J., Matschke M., Garbe L.A. \& Steiner S. 2009: Quantity matters: male sex pheromone signals mate quality in the parasitic wasp Nasonia vitripennis. - Proc. R. Soc. (B) 276: 3303-3310.

Sagarra L.A., Vincent C. \& Stewart R.K. 2001: Body size as an indicator of parasitoid quality in male and female Anagyrus kamali (Hymenoptera: Encyrtidae). - Bull. Entomol. Res. 91: 363-368.

SAgarRa L.A., Vincent C. \& Stewart R.K. 2002: Impact of mating on Anagyrus kamali Moursi (Hym., Encyrtidae) lifetime fecundity, reproductive longevity, progeny emergence and sex ratio. - J. Appl. Entomol. 126: 400-404.

Sмith S.M. \& HubBes M. 1986: Isoenzyme patterns and biology of Trichogramma minutum as influenced by rearing temperature and host. - Entomol. Exp. Appl. 42: 249-258.

SNOOK R.R. 2005: Sperm in competition: not playing by the numbers. - Trends Ecol. Evol. 20: 46-53.

Uzbekov R., Burlaud-Gaillard J., Garanina A.S. \& Bressac C. 2017: The length of a short sperm: elongation and shortening during spermiogenesis in Cotesia congregata (Hymenoptera, Braconidae). - Arth. Struct. Dev. 46: 265-273.

VAN DEN Assem J. 1986: Mating behavior in parasitic wasps. In Waage J. \& Greathead D. (eds): Insect Parasitoids, 13th Symposium of the Royal Entomological Society of London. Academic Press, London, pp. 137-167.

WAAGE J.K. 1986: Family planning in parasitoids: adaptive patterns of progeny and sex allocation. In Waage J. \& Greathead D. (eds): Insect Parasitoids, 13th Symposium of the Royal Entomological Society of London. Academic Press, London, pp. 63-95.

WAJNBERG E. 1994: Intra-population genetic variation in Trichogramma. In Wajnberg E. \& Hassan S.A. (eds): Biological Control with Egg Parasitoids. CAB International, Wallingford, pp. 245-271.

Winer B.J., Brown D.R. \& Michels 1991: Statistical Principles in Experimental Design. 3rd ed. McGraw-Hill, New York, 928 pp.

Received November 30, 2019; revised and accepted May 4, 2020 Published online May 29, 2020 